\title{
DE MEMÓRIA, TRAUMA E FICÇÃO: UM OLHAR SOBRE A NARRATIVA DE BERNARDO KUCINSKI
}

\author{
Joelma Rezende Xavier ${ }^{1}$
}

Resumo: Muitos são os contratempos e prejuízos humanos associados ao período da ditadura militar no Brasil. Os processos de enrijecimento de controle estatal, as estratégias de domínio político-cultural e as tentativas de apagamento da memória marcaram o cotidiano da sociedade durante os anos que envolveram o estado de exceção. Apesar dessa realidade, os relatos de tortura e de denúncia testemunham diferentes versões para os fatos e contêm o poder de ressignificação da memória, especialmente por meio da escrita literária. Este artigo visa a propor uma breve discussão sobre os temas memória e trauma na construção ficcional, a partir da análise de contos publicados na antologia Você vai voltar pra mim e outros contos, de Bernardo Kucinski (2014).

Palavras-chave: literatura; trauma; ditadura militar.

Abstract: There are many human inconveniences and human damages linked to the period of military dictatorship in Brazil. The hardening processes from State control, the political-cultural domain strategies and attempts about the erasure of memory marked the routine of society during the years which surround the State of exception. Despite this reality, the reports of torture and complaint bear witness different versions for the facts and contain the power of ressignification of memory, mainly through the literary writing. This article aims to propose a brief discussion about themes such as memory and trauma in the fictional development, from the analysis of short tales published in the anthology Você vai voltar pra mim e outros contos, by Bernardo Kucinski (2014).

Keywords: literature; trauma; military dictatorship.

\footnotetext{
${ }^{1}$ Doutoranda em Teoria da Literatura e Literatura Comparada junto ao Programa de PósGraduação em Estudos Literários (Póslit) da Faculdade de Letras da UFMG - Universidade Federal de Minas Gerais. Professora do Departamento de Linguagem e Tecnologia do Centro Federal de Educação Tecnológica de Minas Gerais - CEFET/MG - Campus I - Belo Horizonte. E-mail: joelmarexavier@gmail.com.
} 


\section{Introdução}

É possível narrar um trauma? É possível fazer ficção com momentos de repressão? De que maneira a literatura dimensiona/redimensiona vivências traumáticas? Em "Narrar o trauma", Seligmann-Silva (2008, p. 70) afirma que "o trauma encontra na imaginação um meio para sua narração" e que "a literatura é chamada diante do trauma para prestar-Ihe um serviço". Segundo esse autor, de Homero, especialmente em Ilíada, ao teatro pós-Shoah de Beckett, há uma tentativa, por meio da linguagem literária, de interiorizar a cena traumática que, muitas vezes, pode se confundir com a própria história da arte e da literatura. Seligmann-Silva salienta que

[a]prendemos, ao longo do século $X X$, que todo produto da cultura pode ser lido no seu teor testemunhal. Não se trata da velha concepção realista e naturalista que via na cultura um reflexo da realidade, mas, antes, de um aprendizado psicanalítico - da leitura de traços do real no universo cultural. Já o discurso dito sério é tragado e abalado na sua arrogância quando posto diante da impossibilidade de se estabelecer uma fronteira segura entre ele, a imaginação e o discurso literário. (SELIGMANN-SILVA, 2008, p. 71)

É a partir dessa noção de teor testemunhal do literário e, especialmente a partir da relação entre literatura e trauma que proponho uma análise para alguns contos, publicados na obra Você vai voltar para mim e outros contos, de Bernardo Kucinski (Cosac Naif, 2014). Ao longo deste artigo, tentarei tensionar algumas perspectivas, sobretudo, com o intuito de refletir sobre a pergunta: é ético ficcionalizar a opressão da ditadura militar brasileira?

\section{Escrita ficcional e ditadura militar}

A obra Você vai voltar pra mim e outros contos é parte de uma profícua escrita desenvolvida por Kucinski entre os anos 2010 e 2013, período em que o autor produziu cerca de 150 contos. Nessa antologia, há 28 contos selecionados a partir da temática da ditadura militar brasileira. $\mathrm{O}$ autor, em um 
relato sobre sua produção literária ${ }^{2}$, afirma que uma das potências de sua escrita está no fato de ele, como escritor, tensionar o relato do real com a atmosfera ficcional e, a partir daí, ter a possibilidade de "alcançar uma verdade transcendental que nem o mero relato dos fatos nem a ficção alcançariam". Além desse aspecto atribuído a sua escrita, Kucinski ainda destaca que o papel do escritor é "garimpar coisas que ele nem sabia que estavam em sua memória".

Bernardo Kucinski é jornalista, escritor, ex-professor da USP, além de ter trabalhado como assessor da Presidência da República durante o primeiro mandato do presidente Lula. Dentre suas publicações, destaca-se $K$, relato de uma busca - reeditado e publicado em mais de cinco línguas - romance de base autobiográfica em que o autor narra a história de um pai à procura da filha, desaparecida nos anos 1970, no Brasil. A família Kucinski sofreu o trágico desaparecimento de Ana Rosa Kucinski (irmã de Bernardo Kucinski) e de Wilson Silva (marido de Ana Rosa), em abril de 1974. De acordo com relatos do escritor, especialmente na entrevista ao jornal Rascunho ${ }^{3}$, as dificuldades vividas por toda sua família, nesse período, e o sofrimento dessa perda o motivaram a escrever sobre o trágico desaparecimento da irmã. Mesmo quarenta anos depois do ocorrido, a intenção de escrita do romance $K$, relato de uma busca e da coletânea Você vai voltar pra mim e outros contos resulta da necessidade de uma revelação, de uma reflexão sobre as atrocidades e as arbitrariedades ocorridas no período da ditadura militar brasileira: "A literatura me levou à catarse. Não foi a necessidade de catarse que me levou à literatura" (KUCINSKI, fragmento de entrevista ao jornal Rascunho).

Em "Experiência e pobreza", Walter Benjamim critica as tendências da era moderna - a cultura do vidro -, cujos trabalhos técnicos, da arquitetura às produções cinematográficas, parecem privilegiar uma atmosfera de impessoalização dos comportamentos/das memórias, levando ao empobrecimento da experiência humana: "Ficamos pobres. Abandonamos

\footnotetext{
${ }^{2}$ Disponível no site da editora Cosac Naif: https://www.youtube.com/watch?v=Q8YteubgTCw nesse vídeo, publicado em 06 fev. 2014, o autor fala sobre o romance $K$ e o livro de contos Você vai voltar para mim, obras que giram em torno do tema da ditadura militar brasileira (acesso em: 09 nov. 2015).

${ }^{3}$ http://rascunho.gazetadopovo.com.br/a-libertacao-de-kucinski/, Acesso em: 09 nov. 2015. 
todas as peças do patrimônio humano, tivemos de empenhá-las, muitas vezes, a um centésimo do seu valor para recebermos em troca a moeda miúda do atual' (BENJAMIN, 1987, p. 119). Partindo desse estudo de Benjamin e do enfoque sobre algumas obras artísticas relacionadas ao Holocausto, Seligmann-Silva (2008) propõe reflexões sobre os processos de "estetização da catástrofe" e afirma não ser papel da arte/ficção representar o real de forma crua, mas de apresentar, por meio de recursos estéticos/simbólicos, uma visão sobre os processos históricos que esteja comprometida com diversos níveis de significação (político, ético, científico, social etc.). Em relação ao registro dos processos traumáticos associados à ditadura militar vivida na América Latina, Seligmann-Silva (2008) aponta quatro aspectos fundamentais, a saber:

I) a figura dos desaparecidos, nos países latino-americanos, tornou o quadro da memória praticamente impossível: como relatar sobre a memória de quem nunca mais voltou?;

II) as mídias, sobretudo a televisiva, impactaram (e impactam) o registro das imagens: a TV tem o poder de concretizar falsas utopias, especialmente por veicular uma visão de que os traumas foram superados;

III) a impunidade no Brasil e na Argentina ${ }^{4}$ : em ambos os países, o apagamento e o esquecimento das atrocidades cometidas no período da ditadura militar foram institucionalizados por meio de leis que garantiram liberdade de "perdão" aos criminosos. "Mais de 20 anos de Anistia no Brasil: isso equivale a 20 anos de amnésia?" (SELIGMANN-SILVA, 2008, p. 84)

IV) a incompetência do Brasil em analisar as práticas de tortura, os assassinatos, dentre outros crimes, cometidos no período da ditadura militar e a falta de punição aos criminosos.

Diante desse quadro de dificuldades no tratamento da memória, da história e do esquecimento, em especial no período da ditadura militar latino-

\footnotetext{
${ }^{4}$ Seligmann-Silva (2008) destaca, especialmente a Lei del Punto Final (Argentina, lei n. 23.492, dezembro 1986) e a Lei da Anistia (Brasil, Lei 6.683, agosto 1979).
} 
americana, o autor salienta a importância de toda a sociedade enxergar - por meio dos registros históricos e das construções artísticas - os abalos de traumas, cicatrizes e feridas deixados pela ditadura: "Esses traços podem ser lidos por nós, se não nos deixarmos ofuscar pelos holofotes brilhantes de uma sociedade toda 'fascinada' pela mídia." (SELIGMANN-SILVA, 2008, p. 85)

Tomando como base essas reflexões teóricas, os contos de Kucinski, na antologia Você vai voltar pra mim e outros contos, podem ser interpretados, inicialmente, como um processo dinâmico de tensões relacionadas à truculência da ditadura militar brasileira, em especial, pelo fato de o autor problematizar aspectos plurais relacionados a esse período: há perspectivas sobre a realidade de diferentes classes sociais; sobre o olhar alienado de militantes, de militares e de cidadãos comuns; sobre gerações diferentes; sobre sindicalistas e metalúrgicos, sobre moradores das áreas rurais etc. O discurso narrado, nesses contos, potencializa os desafios relacionados à memória, uma vez que:

A memória não obedece apenas à razão porque ela também está relacionada, por um lado, a tradições herdadas, que fazem parte de nossas identidades e que não respondem a nosso controle e, por outro, a sentimentos profundos, como amor, ódio, humilhação, dor e ressentimento, que surgem independentemente das nossas vontades. (ARAÚJO; SANTOS, 2007, p. 96)

Nesse sentido, podemos entender a perspectiva multifacetada da narrativa de Kucinski como um mecanismo de oposição às atitudes (governamentais, institucionais, coletivas ou individuais) que ainda insistem em apagar os vestígios da vivência humana. No prefácio do livro Você vai voltar pra mim e outros contos, Maria Rita Kehl inicia a apresentação da obra com a seguinte pergunta: "quando termina a escrita de um trauma?", opondo-se às reflexões de Adorno sobre a impossibilidade de haver uma poesia após Auschwitz, a psicanalista salienta que, "passado um tempo em que silêncio e estupor são as únicas reações possíveis ante ao evento traumático, as vítimas se põem a falar. Ou a escrever. Não é um capricho. É uma necessidade." ${ }^{5} \mathrm{Em}$ entrevista ao jornal Rascunho, a pergunta de Kehl foi apresentada pelo

\footnotetext{
${ }^{5}$ Do texto "A ironia e a dor", de Maria Rita Kehl, no prefácio do livro Você vai voltar pra mim e outros contos, de Bernardo Kucinski (2014, p. 15).
} 
entrevistador a Kucinski, que respondeu: "Acho que [a escrita do trauma] não termina nunca. Vai se metamorfoseando." É sobre esse processo de metamorfoses do trauma que falarei a seguir, no desenvolvimento da análise de alguns contos de Kucinski, na antologia Você vai voltar pra mim e outros contos.

\section{Memória, narrativa e trauma: uma breve análise}

Começarei minha abordagem a partir dos contos "A beata Vavá" e "A mãe rezadeira", que nos apresentam situações semelhantes: a construção de personagens femininas que, na condição de mães, mobilizam forças, inclusive religiosas, na tentativa de protegerem seus filhos - presos políticos - das mãos dos torturadores. Em "A beata Vavá", o narrador situa-se na condição de ouvinte do relato de um ex-militante que contou, dentre outras lembranças do período da ditadura militar, a história de uma beata, em Salvador: "eu me lembrei da beata Vavá, que faleceu na Bahia no mês passado com cento e dois anos de idade. Não, ela não participou da luta armada, era católica fervorosa, jamais pegaria em armas. Mas fez mais contra a ditadura do que qualquer um de nós". (KUCINSKI, 2014, p. 22). A partir dessa apresentação, o ex-militante fala sobre a popularidade da beata e relata a sua história. O filho de Vavá, Anésio, era estudante de Geologia e tinha dezenove anos, quando foi preso, no quartel da rua Barão de Mesquita, lugar temido por todos, devido à crueldade dos torturadores. Passado um tempo, a beata Vavá, que sempre visitava seu filho e outros presos políticos no quartel, tivera uma visão:

A beata Vavá rezava pelo Anésio todos os dias duas vezes, primeiro de manhã, na missa das sete, depois de tardezinha. Sempre na catedral e sempre na capela lateral perante a imagem de Jesus crucificado. Essa primeira visão the veio numa reza da tarde; ela orava ajoelhada, de olhar fixo na imagem, quando percebeu que Jesus vertia sangue dos punhos, dos tornozelos, logo da boca, e se transmutou rapidamente na imagem de seu filho: viu seu filho Anésio crucificado e vertendo sangue. (KUCINSKI, 2014, pp. 22-23)

O processo místico metaforizado na imagem do filho crucificado levara a beata a procurar uma autoridade da igreja, o Cardeal de Salvador, para 
denunciar o fato de que seu filho estava sendo torturado e para dizer que a visão do cristo-filho crucificado fora um aviso dos céus para que o Anésio fosse retirado das mãos dos algozes na Barão de Mesquita. O fato levou o arcebispo a fazer um contato com o cardeal do Rio de Janeiro que, um pouco resistente, fizera uma intervenção junto ao comandante do primeiro exército, relatando a visão da beata. Após o contato, Anésio fora transferido para a cadeia de Salvador: "só não o transferiram de pronto, depois que se soube, para dar tempo de sumirem as marcas mais denunciadoras das torturas. [...] o pobre rapaz deu entrada na cadeia de Salvador em frangalhos, de dentes quebrados e várias unhas arrancadas, além de sulcos profundos nos tornozelos e punhos." (KUCINSKI, 2014, p. 24). Passado o ocorrido, especialmente, após ouvir de seu filho que ele poderia ter morrido naquela mesma noite em que a mãe conseguira sua remoção, a história se espalhou pela cidade e a beata Vavá tornara-se um símbolo de resistência religiosa, contribuindo com orações, visitas, conselhos etc. a todos que a procuravam, solicitando proteção aos parentes e/ou amigos que estavam nas mesmas condições de Anésio. Como as visitas da beata à cadeia tornaram-se frequentes, ela conseguiu descobrir as preferências do coronel por seus bolos e, a partir dessa percepção, a beata conseguia entrar na cadeia, levando e trazendo cartas, pequenos bilhetes, cigarros, na tentativa de aliviar o desespero de seu filho e de outros presos. A narrativa segue e o caso da aparição do Cristo metamorfoseado se espalhara pela cidade, a ponto de, numa segunda sessão de torturas contra Anésio, a velhinha ter outra visão arrebatadora do cristo-filho ensanguentado e conseguir chegar à cadeia antes da morte de seu filho. $O$ fato percorreu toda a ordem dos militares e, a partir dessa segunda visão da beata, Anésio nunca mais fora torturado. O conto "A beata Vavá" apresenta o mecanismo narrativo de relato dentro do relato - o narrador onisciente que, na condição de um ouvinte, relatanos a história contada por outro personagem, o ex-militante - o que confere ao enredo dinamismo e maior verossimilhança. O processo narrativo desencadeiase num rápido jogo de vozes que intercambiam experiências relacionadas ao sofrimento e, no caso específico da beata, aos mistérios de interferências místicas que muito contribuíram para confrontar a atmosfera de torturas criadas pela situação histórico-política, na qual o conto se ambienta. 
No conto "A mãe rezadeira", não há uma atmosfera de milagres, poderes ou interferências sagradas, mas, de forma análoga à história da beata Vavá, há uma mãe que, desesperada, visita seu filho na cadeia e roga aos céus para protegê-lo. No conto, o recurso da gradação, nas falas da personagem mãe, contribui para a construção de uma atmosfera de humor e, ao mesmo tempo, reveladora das contradições associadas à ignorância de muitas pessoas - no caso, a mãe - e às arbitrariedades presentes nas atitudes de grupos de resistência e nas ações de militares. O conto gira em torno do fato de um exmilitante ter sido preso e sua mãe, ao visitá-lo, sempre indagar pelas condições a que ele era submetido, percebendo os problemas: "- Meu filho, rezei tanto pra você não ser preso." (KUCINSKI, 2014, p. 131). Em seguida, passado mais um tempo em visitas ao filho e recebendo a notícia de que o cárcere seria de 17 anos, a mãe, mais uma vez, falou: "- Meu filho, rezei tanto pra te soltarem logo." (KUCINSKI, 2014, p. 132). Após a repercussão das informações relacionadas à possibilidade de libertação do filho, por meio da inclusão de seu nome na lista de presos políticos em troca do cônsul suíço sequestrado, a mãe pusera-se a acompanhar as informações divulgadas nos jornais, percebendo as mortes dos militantes que tentavam fugir do exílio e as condições de humilhação e de sofrimento a que se submetiam muitos dos brasileiros que, impedidos de voltar a sua terra natal, permaneciam sob o martírio do exílio e da solidão. A mãe, zelosa pela sobrevivência do filho, ao saber que ele não mais seria nomeado para o exílio, manifesta-se, fervorosamente: "- Graças ao bom Deus, meu filho. Eu rezei tanto pra você não ser solto." (KUCINSKI, 2014, p. 134). O movimento acional, presente nas orações maternas, de 'não ser preso' - 'te soltarem logo' - 'não ser solto' demonstra uma aparente contradição do comportamento materno e, simultaneamente, tensiona a situação a que muitas famílias eram submetidas, na expectativa de um tratamento digno aos presos políticos. O enredo, por meio das ações de uma mãe religiosa, acaba por conferir uma atmosfera de ironia sobre a condição apresentada no conto: somente o poder divino para entender os absurdos da ditadura militar.

Os dois contos apresentam situações de "metamorfoses do trauma" que, ambientadas ora em uma situação de sacralização do sofrimento - "A Beata 
Vavá" - ora em uma situação de cotidianidade desse sofrimento - "A mãe rezadeira" - revelam o caráter estético associado às recorrentes imagens de devoção, desespero e atitude (a beata) e de conformidade e devoção (a mãe rezadeira). Seriam as mães-personagens, elaboradas na narrativa de Kucinski, duas Pietàs? Seriam elas as imagens de uma resistência mais lírica (ou irônica) às truculências da realidade política? Questões como essas são evocadas diante da atmosfera ficcional elaborada nesses contos que, de um modo geral, aproximam-se daquilo que Pollak (1992, p. 10) chamou de registro coletivo do trauma: "Existem cronologias plurais, em função de seu modo de construção, no sentido do enquadramento da memória e também em função de uma vivência diferenciada das realidades".

"Ao Roberto, dos seus pais, tios e irmãs, que nunca te esqueceram" (KUCINSKI, 2014, p. 49). Com essas palavras, abre-se "O velório", conto em que se narra a história de sofrimento de um pai, que realiza um funeral-semcorpo. Antunes, pai de Roberto, completa 90 anos e, temendo a própria morte, desiste de esperar pelo retorno do filho vivo ou mesmo pela certeza de seu corpo morto, e presta-Ihe as últimas homenagens: "Os mortos têm de ser enterrados" (KUCINSKI, 2014, p. 50). O pai enterra um paletó, um par de sapatos que foram do filho, já que "seu corpo nunca fora encontrado." (KUCINSKI, 2014, p. 56). O conto desenvolve o ritual fúnebre, potencializando o sofrimento paradoxal associado muito mais às angústias do desaparecimento do que à própria inexorabilidade da morte.

No conto "Joana", o enfoque narrativo também recai sobre o desaparecimento de pessoas, prática tão comum nas ações ditatoriais:

O marido era metalúrgico e se chamava Raimundo. Católico praticante como ela. Vieram do Nordeste em busca de uma vida um pouco melhor em São Paulo. Já tinham então os dois filhos. Aqui Raimundo se ligou a um grupo de Ação Popular que organizava operários nas fábricas.

Um dia, bem cedo, a polícia foi à casa deles e levou Raimundo. Sem mandado de prisão, sem nada. Soube-se depois que ele foi espancado de modo tão brutal que ele morreu no mesmo dia. Seus gritos eram ouvidos em outras celas. Para ocultar o homicídio, no caso doloso e qualificado, pois acompanhado do crime acessório de abuso de autoridade, a polícia cometeu outro crime, o de ocultamento de cadáver. Sumiram com o corpo de Raimundo.

Tudo isso comprovado, depois que acabou a ditadura, por documentos e depoimentos em várias comissões. Só não se 
sabe, nunca se soube, para onde levaram o corpo e como se desfizeram dele. (KUCINSKI, 2014, p. 59)

Tanto em "O velório" quanto em "Joana", o que se apresenta aos olhos do leitor é uma atmosfera de intensa crueldade e desrespeito à dignidade humana. Um cenário de vileza, de abuso de poder e de impunidade. Elementos apontados por Seligmann-Silva (2008) como potencializadores dos processos traumáticos nas ditaduras militares do Brasil e da América Latina. Mais uma vez, podemos notar, na escrita de Kucinski, uma grande preocupação estética em 'apresentar o evento traumático', a partir da autenticidade ficcional em situações de grande credibilidade, na demarcação constitutiva da memória.

Nos contos "Terapia de família" e "A entrevista", o processo narrativo potencializa a representação da pluralidade memorativa. Isso acontece, uma vez que, em ambos os contos, constrói-se uma abordagem na qual o heroísmo da militância é contestado por filhos que se sentiram abandonados pelo pai. Os contos problematizam aspectos de uma memória apenas voltada para a valorização da militância. Em "Terapia de família", narra-se o comportamento de uma família em heroicizar o pai, um ex-militante político que resistiu às agruras da opressão e, liberto na anistia política, descobre as farsas do filho em relação aos estudos e à família. Impossibilitada de agir, a família recorre a um psicanalista, com o intuito de ouvir o filho e, ao mesmo tempo, fazê-lo compreender a grandeza das atitudes paternas. O filho, sempre indignado com as memórias de um abandono, revolta-se contra a família e abandona a terapia:

Falou da vida apertada enquanto o pai esteve preso; do tempão largado na casa da avó no Paraná; da mãe se esforçando, mas tudo o que ela fazia era pelo pai; o filho não contava, não era nada. $E$ acusou o pai de nunca ter perguntado por ele nos seis anos de cadeia e de não saber sequer o que ele estudava na faculdade. Seis anos esperou em vão uma carta do pai, um bilhete, que nunca chegaram. Pra mãe, sim, o pai escrevia sempre, e pra filha de vez em quando.

- Foi quando eu passei a odiar meu pai e me desinteressei de tudo - ele disse ao terapeuta. (KUCINSKI, 2014, pp. 36-37)

Em "A entrevista", narra-se o projeto de uma estudante em entrevistar três filhas de um ex-militante, assassinado pelos torturadores no período da 
ditadura militar. No relato das filhas, há o emprego de uma gradação imagética, responsável pela representação da forma como o pai, para cada uma delas, foi desaparecendo da memória:

- Lembro muito bem, lembro até a hora; foi quando eu vi meu nome na lista dos aprovados no vestibular. Era hora do almoço, não tinha ninguém no departamento, só eu, sozinha no corredor. A lista estava colada na porta. Quando topei com o meu nome, inteirinho, nome e sobrenome, Maria Helena Mariano, logo pensei nele, em como ficaria contente de eu ter entrado na USP, e lamentei ele não estar vivo para eu ir correndo contar. Assumi pela primeira vez que ele estava morto. Naquela hora eu matei meu pai. [...] eu estava excitada demais para ficar triste. (KUCINSKI, 2014, pp. 86-87)

[...] eu só tinha seis anos quando ele sumiu; não entendia nada e ninguém me explicava. Tentava não pegar no sono, esperando ele voltar para me contar uma história, mas ele chegava tarde demais; de manhã, quando eu acordava, ele já tinha saído. [...] para mim, ele não passava de um irresponsável que trocou a família pela política. (KUCINSKI, 2014, pp. 88)

[...] minha mãe estava grávida de mim quando ele foi preso... sou como esses bebês de proveta que não têm pai. Nem sei como é ter pai... acho tudo isso muito triste. (KUCINSKI, 2014, pp. 89)

Nesses dois contos, o aspecto do trauma demarca a situação do conflito familiar que, longe de estabelecer uma conexão positiva com as atitudes de resistência política ao regime militar, coloca em evidência o abandono paterno. Na perspectiva freudiana, "o trauma é descrito como uma resposta a um evento ou a eventos violentos inesperados ou arrebatadores, que não são inteiramente compreendidos quando acontecem, mas retornam mais tarde em flashbacks, pesadelos e outros fenômenos repetitivos." (CARUTH, 2000, p. 111). Esses contos, no mínimo, desestabilizam olhares sobre a magnitude e/ou o heroísmo da militância e, ao mesmo tempo, potencializam perspectivas da memória traumática no contexto familiar. A partir disso, esses enredos potencializam o debate em torno de questões como: De que forma crianças/jovens sobreviveram à ditadura? Seria cruel, analisar a atitude das personagens - 0 filho, no primeiro conto, e as três filhas, no segundo conto - como representantes de um egoísmo pequeno-burguês, incapaz de extrapolar a esfera de convívio íntimo-familiar? Seria legítimo potencializar o discurso dos filhos, tendo em vista os traumas da situação opressiva, que nunca compreenderam, e do qual eles foram vítimas? Indagações como essas 
perpassam o cenário da ficção também no cinema. Os filmes La faute à Fidel ( $A$ culpa é de Fidel - França, dirigido por Julie Gravas, 2006) e $O$ ano em que meus pais saíram de férias (Brasil, dirigido por Cao Hamburger, 2006) também tematizam conflitos vivenciados por crianças que, na condição de filhos de militantes políticos - ambos os filmes se passam na década de 1970 questionam a situação do abandono e das privações a que elas são expostas em função do ativismo político dos pais. O processo narrativo, elaborado tanto nos contos quanto nos dois filmes citados, instaura-se no olhar de uma criança/um jovem e intensifica uma (nova) abordagem crítica que, somente a partir de um distanciamento temporal do período de opressão (os contos, escritos em 2014 e os filmes produzidos em 2006), poderia ser potencializada. Esse trauma familiar existiu/existe e, como todo trauma, ele precisa ser relatado (ainda que somente por meio da experiência ficcional).

Saindo dessa atmosfera de traumas familiares e retornando aos impactos de uma memória demarcada, sobretudo, pelos traumas do corpo torturado, os contos "A instalação", "Sobre a natureza do homem" e "Você vai voltar pra mim"6 constroem uma atmosfera de tensões, denúncias e de muita humilhação, vivenciadas por mulheres na situação de presas políticas. Esses três contos, por dimensionarem (também) uma abordagem sobre a tortura e as atrocidades do período da ditadura militar brasileira, instauram a possibilidade do "registro da repetição", associada ao trauma. Mais uma, duas, três histórias de tortura? Mais um conjunto de relatos (ficcionais) sobre a opressão ditatorial? Não. Definitivamente não. Em toda a antologia, existe um cuidado estético que permite a manutenção de instrumentos que não só potencializam o ficcional como também conferem um trato ético aos fatos vivenciados na história (para responder à pergunta com que iniciei este artigo). Isso se deve, sobretudo, ao fato de o autor adotar uma perspectiva de multiplicidade de olhares e de vozes em sua construção narrativa.

No conto "A instalação", é narrada a história de uma ex-militante política que, após longos anos de tratamento psicanalítico e psiquiátrico, tenta

\footnotetext{
${ }^{6}$ Conto mais curto da antologia e considerado por Kucinski como a narrativa mais pungente da obra.
} 
recuperar-se dos traumas dos anos em que estivera presa, conseguindo, inclusive, livrar-se de um tique nervoso que ela tinha na sobrancelha, toda vez que se recordara dos espancamentos e humilhações sofridas. A personagem, convidada a uma visita à casa de uma prima - a quem ela não conhecia descobre que o falecido marido de sua prima era um torturador:

A cozinha era ampla. No centro, um fogão a lenha fora de uso, de alvenaria e cimentado vermelho, servia de suporte a uma montagem inusitada, que nossa personagem achou muito bonita e original. Parecia uma instalação de arte antropofágica. Finalmente uma obra de bom gosto, pensou.

A peça era composta de cachos de bananas carnudas e abundantes envolvendo um longo vergalhão de madeira envelhecida, erguido com um totem. Os bagos de banana iam do verde profundo ao dourado voluptuoso, passando pelo amarelo-ouro, o laranja, o marrom, um completo arco-íris tropicalista. Curiosa, ela perguntou:

- E essa coisa tão bonita, o que é?

- São pencas de banana que eu deixo aí pra madurar.

- E aquela haste no meio?

- É a lembrança do meu marido; é o pau de arara que o Oswaldo ganhou dos colegas quando se aposentou da polícia.

Ela sentiu um frio subindo pela barriga e logo o beliscar pesado dos tiques na sobrancelha. (KUCINSKI, 2014, p. 137)

A agilidade dos diálogos e o recurso descritivo, empregados nesse conto, contribuem para a construção de uma perspectiva sarcástica e, ao mesmo tempo, cruel, por revelar o contato póstumo de uma torturada com a mulher e com toda a aura perversa do torturador. Além disso, a velocidade com que se misturam os elementos de uma decoração kitsch e os fragmentos de uma memória torturada transita entre o nonsense e o mais obscuro lado da realidade.

Em "Sobre a natureza do homem", Kucinski narra a história da estudante Imaculata que foi presa por ser colega de faculdade de um militante político. Imaculata foi duramente torturada e, quando retorna a casa, não consegue livrar-se das memórias das torturas, ficando louca. Os pais, diante do quadro da estudante, decidem interná-la em um hospital psiquiátrico, onde Imaculata sofreu novas torturas e fora estuprada. O conto termina com um diagnóstico de ruptura mental da personagem que, incapaz de retomar sua dignidade, ficara para sempre maculada pelas cicatrizes da ditadura militar. O clima trágico do conto não deixa de demarcar um tom sarcástico à realidade política que 
hostilizou/maculou Imaculatas, Marias, Joanas e muitas outras vidas em nome da repressão política daquele período.

O conto "Você vai voltar pra mim" inicia-se com a fala do torturador: "Veja bem o que vai dizer, não esqueça que depois você volta pra cá; você volta pra mim" (KUCINSKI, 2014, p. 69). Essa sentença, de caráter totalmente intimidador, não só motiva o título do conto (e do livro), como também é responsável pela atmosfera de horror a que é submetida a personagem que, após o momento de desespero de seu julgamento na Justiça Militar, sobretudo no apelo ao quadro de constantes torturas a que ela era exposta, é enganada quanto à sua remoção do Dops:

De novo está no camburão. Percebe que é o mesmo que a trouxe e se inquieta. Passa a observar o trajeto pela grade de ventilação. Vê, aterrorizada, entrarem pelo mesmo portão através do qual haviam saído para o tribunal.

O camburão se abre.

O torturador diz, sorrindo:

- Eu disse que você ia voltar pra mim, não disse? Vem, benzinho, vamos brincar um pouco.

Ele a agarra pelas canelas e a arrasta para fora.

Os outros em volta riem. (KUCINSKI, 2014, p. 71)

O conto é curto e apresenta um ritmo ágil, que contribui para tensionar a atmosfera de desespero e de visceralidade da narrativa. A concisão de todo o enredo também potencializa um clima de denúncias acerca da arbitrariedade militar e, especialmente, acerca da humilhação a que foram submetidas as vítimas do regime ditatorial militar no Brasil.

\section{Vestígios de uma memória tatuada na escrita}

Para Walter Benjamin (2012, p. 11), "articular historicamente o passado não significa reconhecê-lo 'tal como ele foi'. Significa apoderarmo-nos de uma recordação (Erinnerung) quando ela surge como um clarão num momento de perigo". Partindo dessa reflexão, podemos ver no trabalho ficcional de Você Vai voltar pra mim e outros contos, um grande esforço de Bernardo Kucinski em potencializar essa 'recordação' por meio de sofrimento, tortura, cicatrizes, 
assassinatos, crueldade nos corpos que jamais esquecerão os traumas vividos na ditadura militar brasileira. 'Recordação' que não só demarca as incongruências do passado como também tenta lançar luz a um futuro politicamente mais articulado e a um leitor mais consciente da memória e das realidades/ficções de seu povo. O processo ficcional desenvolvido por Kucinski, nessa antologia de contos, configura o que Nestrovski (2000, p. 203) chamou de capacidade de reencenar "as vivências do corpo em cada leitor; uma forma particular de inteligência da escrita". Além disso, Kucinski também elabora possibilidades de um combate ao esquecimento. Em sua escrita, os vestígios da experiência humana estão fortemente assinalados e explorados em perspectivas multifacetadas e dinâmicas (da forma como devem ser os registros da vida e do humano).

\section{REFERÊNCIAS}

ARAÚJO, Maria Paula Nascimento; SANTOS, Myrian Sepúlveda dos. História, memória e esquecimento: Implicações políticas. Revista Crítica de Ciências Sociais, n. 79, pp. 95-111, dez. 2007. Disponível em: http://www.ces.uc.pt/publicacoes/rccs/artigos/79/RCCS79-095-111-

MPNascimento-MSepulveda.pdf, acesso em jul. 2009.

BENJAMIN, Walter. Experiência e pobreza. In:

Magia e técnica, arte e política: Ensaios sobre literatura e história da cultura. trad. Sérgio Paulo Rouanet. v. 1. São Paulo: Brasiliense, 1987, pp. 114-119. (Obras escolhidas; v. 1)

. Sobre o conceito da história. In: O anjo da história. Org. e trad. João Barrento. Belo Horizonte: Autêntica Editora, 2012, pp. 7-20. CARUTH, Cathy. Modalidades do despertar traumático (Freud, Lacan e a ética da memória). In: NESTROVSKI, Arthur; SELIGMANN-SILVA, Márcio (org.). Catástrofe e Representação. São Paulo: Escuta, 2000, pp. 111-136.

KUCINSKI, Bernardo. Você vai voltar pra mim e outros contos. São Paulo: Cosac Naif, 2014, 192 p. 
K. Relato de uma busca. São Paulo: Cosac Naif, 2014, 192 p.

NESTROVSKI, Arthur. Vozes de crianças. In: NESTROVSKI, Arthur; SELIGMANN-SILVA, Márcio (org). Catástrofe e Representação. São Paulo: Escuta, 2000, pp. 185-206.

REIS FILHO, Daniel Aarão; RIDENTI, Marcelo; MOTTA, Rodrigo Patto Sá (org.). A ditadura que mudou o Brasil: 50 anos do golpe de 1964. Rio de Janeiro: Zahar, 2014, 267 p.

SELIGMANN-SILVA, Márcio. Reflexões sobre a memória, a história e o esquecimento. In: SELIGMANN-SILVA, Márcio (org.). História, Memória e literatura: o testemunho na era das catástrofes. Campinas, SP: Ed. da Unicamp, 2003, pp. 59-89.

. Narrar o trauma: a questão dos testemunhos de catástrofes históricas.

Psicologia clínica, v. 20, n.1, Rio de Janeiro, pp. 65-82, 2008. Disponível em: http://www.scielo.br/scielo.php?pid=S0103-

56652008000100005\&script=sci arttext; Acesso em: 15 nov. 2015.

\section{Endereços eletrônicos pesquisados:}

- https://www.youtube.com/watch?v=Q8YteubgTCw, Acesso em: 15 nov. 2015

- http://rascunho.gazetadopovo.com.br/a-libertacao-de-kucinski/, Acesso em: 09 nov. 2015.

- http://kucinski.com.br/, Acesso em: 09 nov. 2015.

- http://www.gazetadopovo.com.br/caderno-g/colunistas/josecastello/escrita-de-libertacao-evyz4bgbai1067x0nfi1a30i6, Acesso em: 09 nov. 2015.

- Revista Cult, edição 187 http://revistacult.uol.com.br/home/2014/02/memorias-de-um-tempo-quenao-deve-ser-esquecido/, Acesso em: 15 nov. 2015. 